\title{
Comparative investigations of equatorial electrodynamics and low-to-mid latitude coupling of the thermosphere-ionosphere system
}

\author{
M. J. Colerico ${ }^{1}$, M. Mendillo ${ }^{2}$, C. G. Fesen ${ }^{3}$, and J. Meriwether ${ }^{4}$ \\ ${ }^{1}$ MIT Haystack Observatory, Westford, Massachusetts, USA \\ ${ }^{2}$ Center for Space Physics, Boston University, Boston, Massachusetts, USA \\ ${ }^{3}$ Department of Physics and Astronomy, Dartmouth College, Hanover, New Hampshire, USA \\ ${ }^{4}$ Department of Physics and Astronomy, Clemson University, Clemson, South Carolina, USA
}

Received: 4 October 2005 - Accepted: 16 December 2005 - Published: 23 March 2006

\begin{abstract}
The thermospheric midnight temperature maximum (MTM) is a highly variable, but persistent, large scale neutral temperature enhancement which occurs at low latitudes. Its occurrence can impact many fundamental upper atmospheric parameters such as pressure, density, neutral winds, neutral density, and F-region plasma. Although the MTM has been the focus of several investigations employing various instrumentation including photometers, satellites, and Fabry-Perot interferometers, limited knowledge exists regarding the latitude extent of its influence on the upper atmosphere. This is largely due to observational limitations which confined the collective geographic range to latitudes within $\pm 23^{\circ}$. This paper investigates the MTM's latitudinal extent through all-sky imaging observations of its $6300 \AA$ airglow signature referred to by Colerico et al. (1996) as the midnight brightness wave (MBW). The combined field of view of three Southern Hemisphere imaging systems located at Arequipa, Peru, and Tucuman and El Leoncito, Argentina, for the first time extends the contiguous latitudinal range of imager observations to $8^{\circ} \mathrm{S}-39^{\circ} \mathrm{S}$ in the American sector. Our results highlight the propagation of MBW events through the combined fields of view past $39^{\circ} \mathrm{S}$ latitude, providing the first evidence that the MTM's effect on the upper atmosphere extends into mid-latitudes. The observations presented here are compared with modeled $6300 \AA$ emissions calculated using the NCAR thermosphere-ionosphereelectrodynamic general circulation model (TIEGCM) in conjunction with an airglow code. We report that at this time TIEGCM is unable to simulate an MBW event due to the model's inability to reproduce an MTM of the same magnitude and occurrence time as those observed via FPI measurements made from Arequipa. This work also investigates the origins of an additional low latitude airglow feature referred to by Colerico et al. (1996) as the pre-midnight
\end{abstract}

Correspondence to: M. J. Colerico

(colerico@ haystack.mit.edu) brightness wave (PMBW) and described as an enhancement in $6300 \AA$ emission which occurs typically between 20:0022:00 LT and exhibits equatorward propagation. We present the first successful simulation of a PMBW event using the TIEGCM and the airglow code. We find that the PMBW's origin is electro-dynamical in nature, resulting from the expected evening decay of the inter-tropical arcs.

Keywords. Ionosphere (Equatorial ionosphere; Modeling and forecasting)

\section{Introduction}

The thermospheric Midnight Temperature Maximum (MTM) is a highly variable, but persistent, large scale neutral temperature enhancement which occurs at low latitudes. The magnitude of the MTM is reported to be in the range of 20-200 K (Sobral et al., 1978; Spencer et al., 1979; Burnside et al., 1981; Rao and Sastri, 1994; Colerico et al., 1996; Colerico and Mendillo, 2002; Faivre et al., 2005) developing initially near the geographic equator and exhibiting apparent poleward propagation (Herrero and Spencer, 1982). The development of an MTM has the possibility of producing a host of modifications in other fundamental upper atmospheric parameters. Spencer et al. (1979) showed that recurrent nighttime enhancements in neutral temperature were correlated with a poleward surge in the typically equatorward nighttime meridional neutral winds due to the midnight pressure bulge (MPB) which accompanies the MTM. In turn, this poleward wind modification may affect the vertical transport of plasma down magnetic field lines to lower altitudes where it can dissociatively recombine to produce $6300 \AA$ airglow emissions (Behnke and Harper, 1973). Nelson and Cogger (1971) were the first to identify the relationship between the appearance of a $6300 \AA$ post midnight enhancement and the downward

Published by Copernicus GmbH on behalf of the European Geosciences Union. 
descent of the F-region plasma. The authors referred to these two features as the "post-midnight enhancement" and the "midnight descent", respectively. Later, Behnke and Harper (1973) referred to the "midnight descent" as the "midnight collapse". The MTM's ability to influence the nighttime behavior of the low latitude thermosphere on a fundamental level requires attention to be focused on understanding its generation mechanisms, characteristics, and level of influence on other upper atmospheric parameters.

During the late 1970's and early 1980's significant attention was focused on MTM observations in the American sector addressing issues regarding its basic characteristics such as occurrence time, magnitude, and seasonal behavior as well as its impact on other atmospheric parameters (Herrero et al., 1993, and references therein). Due to observational limitations which confined these investigations to a geographic latitude range within $\pm 20^{\circ}$, limited knowledge was obtained regarding the latitude extent of the MTM's poleward propagation and upper atmospheric influences. Studies employing various instrumentation such as photometers (Sobral et al., 1978), satellites (Herrero and Spencer, 1982), and FPIs (Meriwether et al., 1986) reported on the passage of the MTM out of their fields of view to higher latitudes. None witnessed the termination of the MTM's poleward movement.

Colerico et al. (1996) made the first 2-D ground based observations of the MTM through its $6300 \AA$ airglow signature, the midnight brightness wave (MBW), using an all-sky imaging system in operation in Arequipa, Peru $\left(16.2^{\circ} \mathrm{S}, 71.5^{\circ} \mathrm{W}\right)$. The authors described the MBW as a recurring enhanced $6300 \AA$ airglow feature which exhibited apparent north-east to south-west propagation through the field of view near local midnight. These MBW events passed overhead within a two hour time frame with an apparent phase velocity of $200-400 \mathrm{~m} / \mathrm{s}$. The analysis of simultaneous neutral wind and temperature measurements made by an FPI collocated with the Arequipa imager revealed a strong correlation between the passage of MBW events with temperature enhancements between 100-200 K and poleward reversals/ abatements in the meridional wind. This was consistent with the Spencer et al. (1979) results, thus confirming the relationship between the MTM and MBW. All of the MBW events observed by the imager passed through its latitudinal field of view of $8^{\circ} \mathrm{S}$ to $23^{\circ} \mathrm{S}$ which placed a solid lower limit on the MTM's poleward propagation but provided no additional information regarding its total latitude extent.

Colerico et al. (1996) reported on another persistent, enhanced $6300 \AA$ airglow feature observed by the Arequipa imager, referred to as the pre-midnight brightness wave (PMBW). PMBW events typically occurred early in the evening between 20:00-22:00 LT with a propagation direction opposite that of an MBW from south-west to north-east. Though not as frequent as MBW events, the PMBW was a regular feature in the imaging data often occurring with, but not exclusively accompanied by, an MBW event. The authors reported that PMBW events were often correlated with neutral wind and temperature patterns similar to those observed during MTM events. However, it was not clear whether the MTM was responsible for the development of both MBW and PMBW airglow features.

In this study, we employ a chain of three all-sky imaging systems with overlapping fields of view located at Arequipa, Peru, and Tucuman and El Leoncito, Argentina to examine $6300 \AA$ airglow observations over a combined latitude range of $8^{\circ} \mathrm{S}-39^{\circ} \mathrm{S}$. This presents the first opportunity to explore the extent of the MTM's influence past $39^{\circ} \mathrm{S}$. Our results highlight the first evidence of the MBW's propagation through this extended latitudinal coverage into mid-latitudes in the American sector. This suggests that significant low to mid latitude coupling of the thermosphere-ionosphere system exists during MTM events via its influence on fundamental upper atmospheric parameters. We present the first view of the MBW's averaged poleward propagation path past $39^{\circ} \mathrm{S}$ under equinox conditions using averaged $6300 \AA$ airglow data from Arequipa and Tucuman during October 1996 and El Leoncito during April 2000. Averaged October 1996 FPI measurements of neutral wind and temperature are presented as a descriptor of the MTM's effect on upper atmospheric neutral parameters.

We model $6300 \AA$ airglow emissions using the NCAR Thermosphere-Ionosphere-Electrodynamic General Circulation Model (TIEGCM) in conjunction with an airglow model (Mendillo et al., 1993; Semeter et al., 1996) for geophysical conditions similar to those during October 1996, i.e. magnetically quiet, solar minimum, equinox, in an attempt to reproduce PMBW and MBW events. The modeled airglow as well as the TIEGCM neutral winds and temperatures are compared with the October 1996 averaged imaging observations and FPI measurements. The model results include the successful simulation of a PMBW event. Further analysis of additional TIEGCM simulated parameters indicate that the PMBW's origins are electrodynamical in nature, stemming from the reversal of the fountain effect and expected decay of the intertropical arcs. Attempts at simulating the MBW proved unsuccessful, likely due to the model's inability to reproduce an MTM of strong enough magnitude to instigate the upper atmospheric modification required for enhanced $6300 \AA$ production. We discuss the MTM's generation mechanism and suggest that additional higher order, upward propagating tidal modes from the lower atmosphere and their interactions may be necessary for accurate simulation of the MTM within the model.

\section{Instrumentation}

As part of the NSF CEDAR MISETA Program (MultiInstrumented Studies of Equatorial Aeronomy), an all-sky, image-intensified CCD camera system was in operation in Arequipa, Peru $\left(16.2^{\circ} \mathrm{S}, 71.35^{\circ}\right)$, from October 1993 
to October 2000. An additional (ONR sponsored) imaging system was installed in Tucuman, Argentina $\left(26.47^{\circ} \mathrm{S}\right.$, $\left.65.15^{\circ} \mathrm{W}\right)$, in September 1996 , and was subsequently moved to El Leoncito, Argentina (31.8 $\left.\mathrm{S}, 69.0^{\circ} \mathrm{W}\right)$, in May 1999. A detailed description of these imaging systems can be found in Baumgardner et al. (1993) and Mendillo et al. (1997). Figure 1 illustrates the geographic locations of the three Southern Hemisphere imaging systems used in this study. The circles represent $75^{\circ}$ of their fields of view (elevation angles ranging from $15^{\circ}-90^{\circ}$ ) at an altitude of $300 \mathrm{~km}$. These overlapping fields of view, encompassing the $70^{\circ} \mathrm{W}$ meridian, facilitate the first opportunity for airglow observations over the extended geographic latitude range of $8^{\circ}-39^{\circ} \mathrm{S}$.

These fully automated imaging systems ran for a two week window each month centered on the new Moon. Images were taken at multiple wavelengths and exposure times. Each imager was equipped with a set of oxygen emission line filters at $5577 \AA, 6300 \AA$, and $7774 \AA$, along with an off-band control filter at $6444 \AA$ used for photometric calibration of the $6300 \AA$ images. Each of these wavelengths provides unique information regarding the approximate altitude regime in which a given airglow feature develops. The $7774 \AA$ emission results from the radiative recombination of $\mathrm{O}^{+}$and $\mathrm{e}^{-}$ at F-region altitudes given by the reaction

$\mathrm{e}^{-}+\mathrm{O}^{+} \rightarrow \mathrm{O}+\mathrm{hv}$

The peak of $7774 \AA$ emissions occurs near $\mathrm{h}_{\text {max }}$, the altitude of F-region peak electron density, which can be $>400 \mathrm{~km}$ during post sunset periods. The dissociative recombination of $\mathrm{O}_{2}^{+}$through the reactions

$\mathrm{O}_{2}+\mathrm{O}^{+} \rightarrow \mathrm{O}_{2}^{+}+\mathrm{O}$

$\mathrm{O}_{2}^{+}+\mathrm{e}^{-} \rightarrow \mathrm{O}+\mathrm{O}^{*}$

produces $6300 \AA$ or $5577 \AA$ airglow depending on the state of $\mathrm{O}^{*}$ at F-region altitudes between $250-350 \mathrm{~km}$ (Rees, 1989).

In general, the MTM develops below $h_{\max }$ in the approximate altitude range of $200-400 \mathrm{~km}$ (Herrero and Spencer, 1982). Mendillo et al. (1997) reported that while the MBW was observed in both the $5577 \AA$ and $6300 \AA$ emissions, it was absent in the $7774 \AA$ observations. This is consistent with the Herrero and Spencer (1982) findings. In the Fregion, $5577 \AA$ is a weaker emission than $6300 \AA$. Taking this into consideration, the work presented here focuses on observations and modeling of the low latitude $6300 \AA$ emission which is sensitive to the dynamics occurring in the altitude region in which the MTM develops.

Also indicated in Fig. 1 is the location of an FPI collocated with the Arequipa imaging system. The FPI has been in operation in Arequipa since 1983 (Meriwether et al., 1986; Biondi et al., 1990, 1991). The system was upgraded for MISETA, making coincident measurements with the imaging system between October 1993 and October 2000. The

\section{Southern Hemisphere All-Sky Imaging Sites}

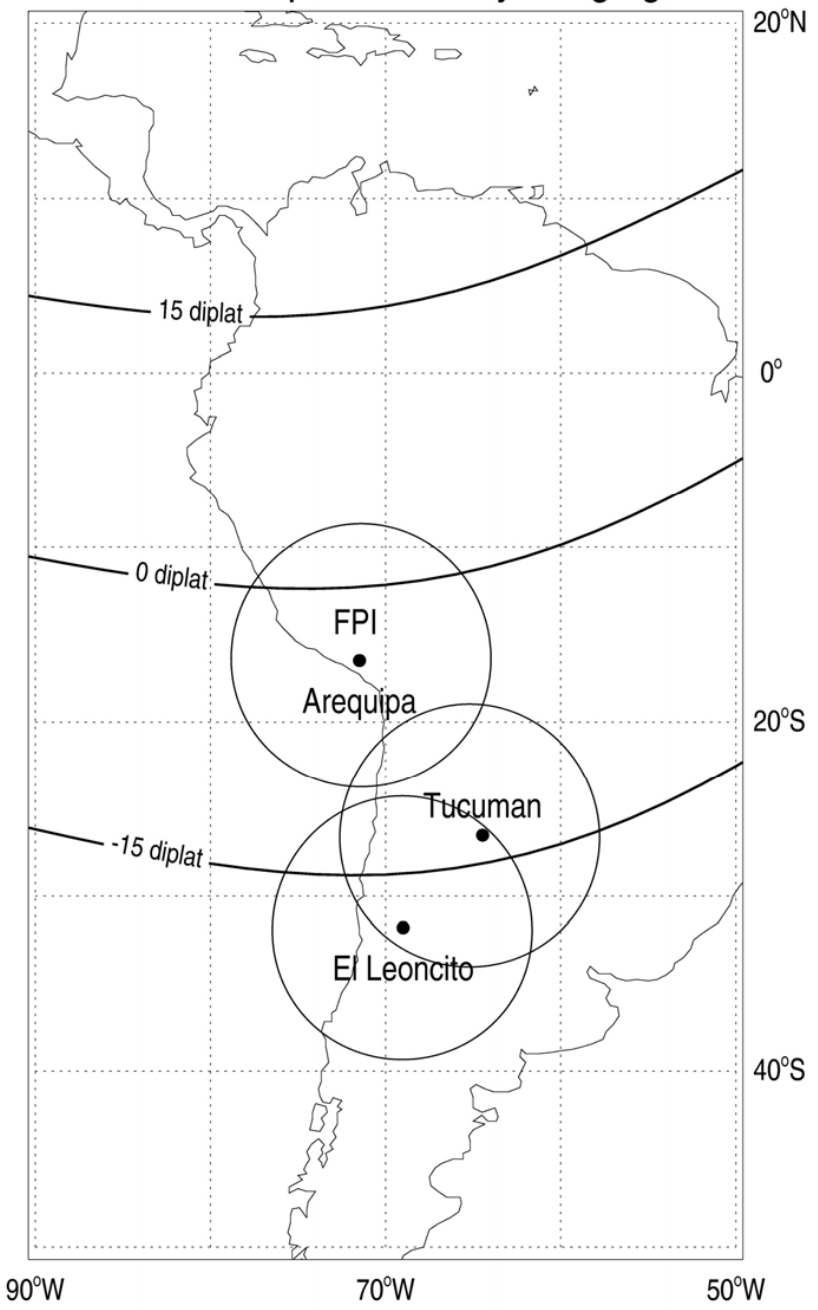

Fig. 1. The geographic locations of three Southern Hemisphere allsky imaging systems used in this study. The circles represent $75^{\circ}$ of the fields of view at $300 \mathrm{~km}$ with the dots representing the zeniths of the imagers. The location of a FPI is also indicated at Arequipa's location.

measurements made by the FPI include thermospheric neutral winds and temperatures, and $6300 \AA$ intensity. FPI measurements were made in the four cardinal directions; north, south, east, and west at a zenith angle of $60^{\circ}$.

\section{Observations}

\section{$3.16300 \AA$ all-sky imaging observations}

Colerico et al., (1996) investigated the seasonal dependence of MBW occurrences and found that while MBW events were observed in all seasons, they occurred predominantly during equinox months. The data sets chosen for the study presented here consist of the equinox periods October 1996 


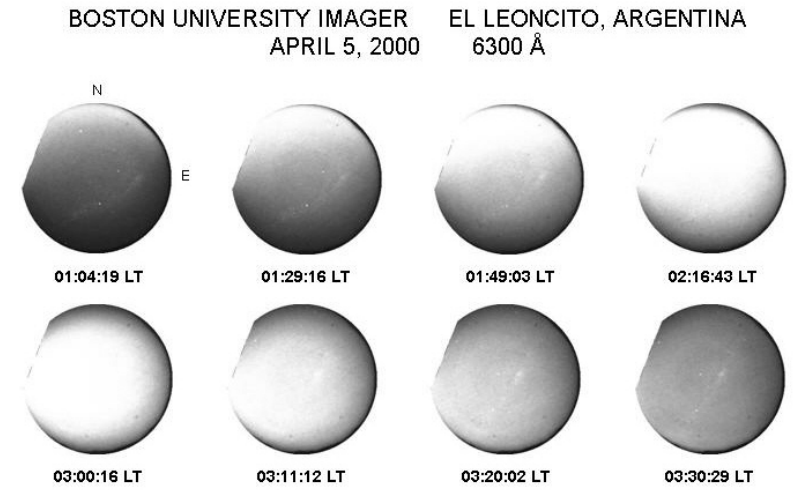

Fig. 2. A series of eight $6300 \AA$ all-sky images taken from El Leoncito, Argentina on 5 April 2000 which illustrates the passage of an MBW event. The orientation of the images is such that North and East are at the top and to the right, respectively.

for Arequipa and Tucuman and April 2000 for El Leoncito. Ideally, the data sets would have been common at all sites, but this was not possible for a variety of weather and logistical reasons. The differences in the equinox conditions for fall versus spring were ignored, since on average the MTM behaves similarly in both seasons (Herrero and Spencer, 1982).

Figure 2 displays a series of eight $6300 \AA$ all-sky images taken from El Leoncito on 5 April 2000, which illustrates the passage of an MBW event. The orientation of the images is such that north and east are at the top and right of each image, respectively. The MBW is seen as the enhanced airglow feature propagating from north-east to south-west through the field of view. This presents the first indication that the MTM's influence on the upper atmosphere extends past the previous observational limit of $23^{\circ}$ into mid-latitudes in the Southern Hemisphere of the American sector.

A meridional intensity scan is a valuable data analysis tool used in the identification and examination of the meridional propagation of $6300 \AA$ airglow enhancements observed in the all-sky imaging data such as PMBW and MBW events. It is constructed by taking a vertical slice through the zenith of each image taken over the course of an evening and stacking them in chronological order. Each image included in the meridional intensity scan was corrected for $6444 \AA$ A background contamination as well as vignetting and van Rhijn effects. Figure 3 presents a meridional intensity scan for the evening of the 5 April 2000, MBW event shown in Fig. 2. The MBW enters El Leoncito's field of view at approximately 02:00 LT and exits to the south near 03:15 LT. The black line indicates a linear fit to the MBW's poleward propagation path. The southern Appleton anomaly crest can also be seen as the enhanced airglow feature observed earlier in the evening between 19:30-23:30 LT in the latitude range of $24^{\circ}-30^{\circ} \mathrm{S}$. It is important to note the exit of the MBW event from El Leoncito's field of view, setting a new lower limit on

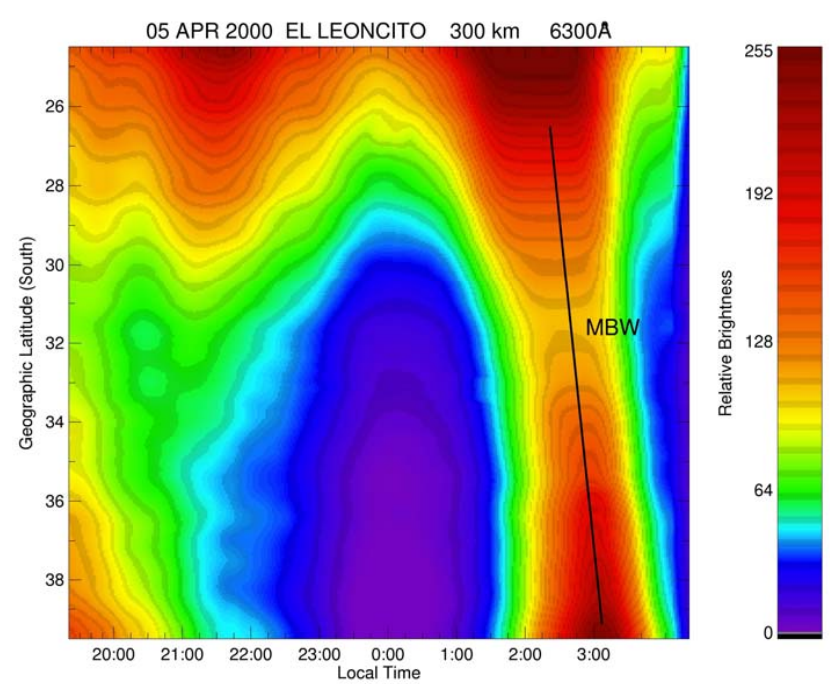

Fig. 3. A meridional intensity scan constructed from data taken by the El Leoncito imager on the evening of 5 April 2000. The MBW event is clearly evident in this scan. The MBW enters the field of view from the north at approximately 02:00 LT and exits to the south near 03:15 LT. The black line indicates a linear fit to the MBW's poleward propagation path.

the MTM's poleward propagation at $39^{\circ} \mathrm{S}$ in the American sector.

The average of all individual meridional intensity scans within a given monthly two week operation window can provide a measure of the overall behavior of airglow emissions during that time period, accentuating any persistent meridional propagation features within the data set, as shown in Colerico and Mendillo (2002) for Arequipa. Averaged scans are more suitable for comparison with model calculations than individual meridional intensity scans which can exhibit day to day variabilities. For instance, variabilities may reflect variations in magnitude, latitudinal range and duration of the southern Appleton anomaly crest, or in the MBW's occurrence, magnitude and propagation speed. Figure 4 shows a composite averaged meridional intensity scan constructed by merging averaged meridional scans for each of the three data sets selected for this study. The averaged Arequipa and Tucuman meridional scans were constructed from 14 and 6 nights of data during October 1996, respectively. The El Leoncito averaged meridional scan included 5 nights of data taken during March-April 2000. The selection criterion was such that all evenings with favorable weather conditions were included in the averages. The absence of Tucuman data in the composite scan between 20:00-22:30 LT is due to persistent, poor weather conditions early in the evenings. The first feature of note is the averaged latitudinal location of the Southern Hemisphere anomaly crest during October 1996 and April 2000, indicated by the brackets. Under solar maximum conditions, $\mathrm{F}_{10.7}=185.5$, the anomaly crest is positional farther south and extends farther into the nightside 

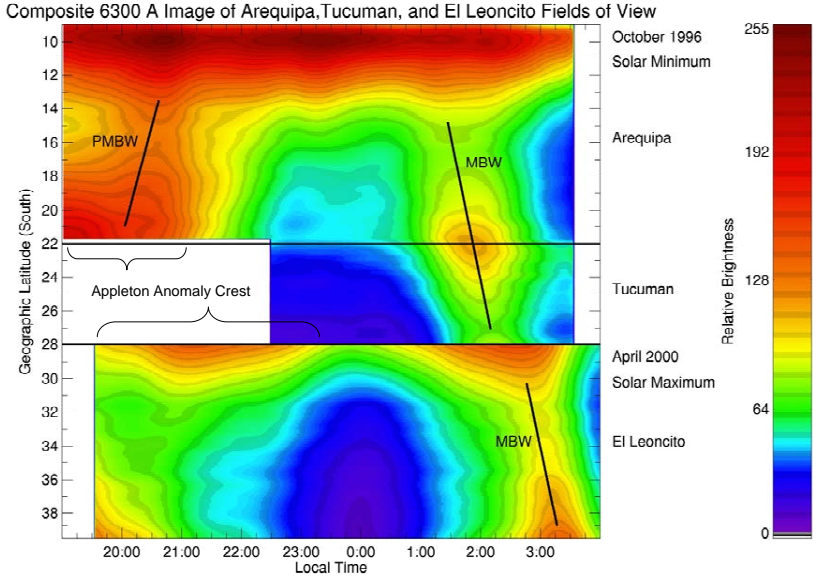

Fig. 4. A composite averaged meridional intensity scan constructed from the combination of the averaged Arequipa, Tucuman, and El Leoncito data sets. The Arequipa and Tucuman sections of the image include 14 and 6 nights of data, respectively, taken during October 1996. The El Leoncito segment includes five nights of data taken during March-April, 2000. The PMBW and MBW events are labeled and linear fits to their propagation paths are indicated by the black lines. The location of the Appleton anomaly crest is indicated by the brackets.

ionosphere than during October 1996 solar minimum conditions where the averaged $\mathrm{F}_{10.7}=99.7$.

The MBW and PMBW events, present in the averaged scan, are labeled and linear fits to the data are indicated by the black lines. The appearances of the PMBW and MBWs in Fig. 4 point to the persistence of these airglow features throughout the data sets. The PMBW's location is confined to the latitudinal range between the anomaly crest and the geomagnetic equator $\left(\sim 11^{\circ} \mathrm{S}\right.$ geographic latitude). This composite image provides the first observations of the MBW's complete propagation path from $8.5^{\circ} \mathrm{S}$ through $39^{\circ} \mathrm{S}$ in the American sector. Where Fig. 3 indicated that the MTM occurrences can affect the mid-latitude thermosphere-ionosphere system, the averaged results show that this is a routine occurrence.

Even though the Tucuman and El Leoncito fields of view overlap considerably, there is an approximately 45 -min shift in the average MBW occurrence time in the composite meridional scan. This is most likely due to the difference in the sampled time periods; however, these results also suggest possible solar cycle dependencies in the MBW occurrence. Brief mention of a proposed relationship between the MTM and solar flux occurred in Herrero et al. (1983) which investigated latitude variations in the MTM using data from the AE-E seasonal temperatures maps discussed by Herrero and Spencer (1982). The authors stated that although there was not enough data to characterize the sources of the neutral temperature variations, it should carry some dependence on
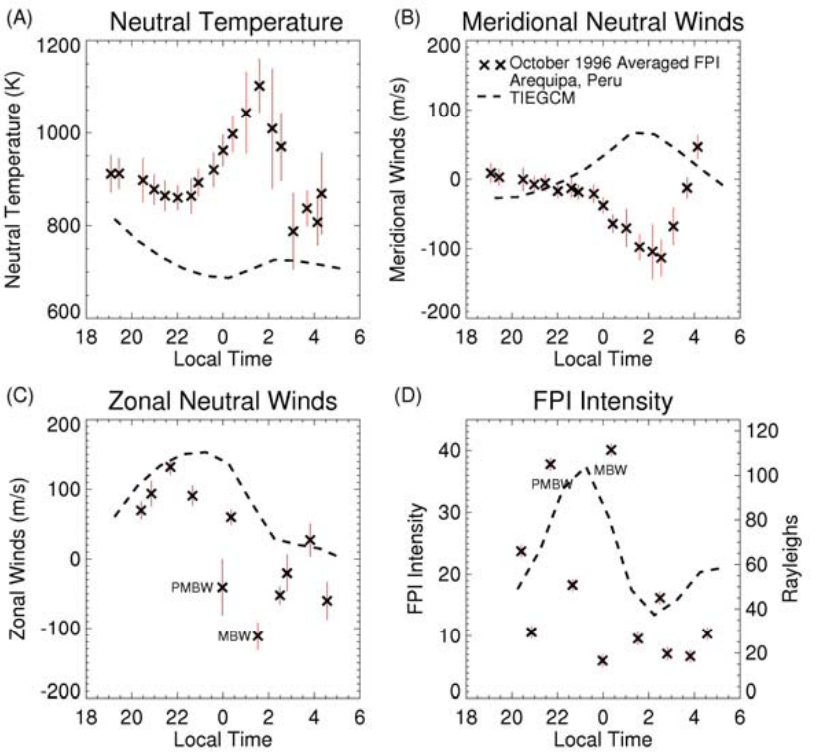

Fig. 5. A comparison between October 1996 averaged FPI measurements taken from Arequipa (the x's) and the equivalent TIEGCM modeled parameters (the dashed lines) at $17.5^{\circ} \mathrm{S}$ latitude under similar geophysical conditions; equinox, solar minimum, magnetically quiet. (A) Neutral temperature, (B) Meridional neutral winds. Positive values indicate northward winds. (C) Zonal neutral winds. Positive values indicate eastward winds. (D) FPI intensity. Left-side axis denotes FPI intensity. Right-side axis denotes Rayleighs.

solar flux, gravity waves, and magnetic activity, in addition to other spontaneous sources.

\subsection{FPI measurements}

FPI measurements of neutral temperature, meridional and zonal winds, and the intensity of $6300 \AA$ emissions were taken from Arequipa during the October 1996 imaging operation period. The averages of these neutral parameters over the October 1996 operation period are plotted in Fig. 5. A bin size of $0.5 \mathrm{~h}$ was used in the averaging. The MTM and its neutral parameter signatures are clearly identifiable. Figure 5A shows a significant temperature enhancement of approximately $200 \mathrm{~K}$ between 00:00-02:00 LT which is correlated with a poleward increase in the meridional winds (Fig. 5B). These neutral wind and temperature modifications coincide with the appearance of the MBW between 01:0003:00 LT in the averaged observations in Fig. 4. This correlation is consistent with previous studies by Colerico et al. (1996). FPI intensity is an indicator of $6300 \AA$ emissions. The MBW's passage is also observed in the FPI intensity plotted in Fig. 5D. The peak in the FPI intensity associated with the MBW occurs at approximately 00:30 LT and is labeled.

The averaged zonal winds plotted in Fig. 5C exhibit a reversal of the typically eastward direction to westward 
between 00:30 LT-2:00 LT. The reversal is also correlated with the passage of the $\mathrm{MBW}$, and the minimum is labeled "MBW" in the figure. This is in agreement with Herrero et al. (1985) which reported on MTM induced abatements in the normally eastward zonal winds as observed by the Dynamics Explorer-2 (DE-2) satellite. Zonal winds near the equator can be locally influenced by ion-drag and the zonal component of the pressure gradient. Herrero et al. (1985) found that a significant pressure increase near midnight such as the MPB which accompanies the MTM could result in a zonal wind reversal from eastward to westward.

The PMBW's occurrence in the averaged airglow observations is also observed in the FPI intensity measurements between 21:00 LT-22:30 LT. Its peak is labeled "PMBW". The PMBW's detection in FPI intensity measurements is not correlated with a temperature enhancement or a meridional wind modification. Colerico et al. (1996) reported patterns in meridional wind and temperature during October 1994 PMBW events which were similar to those observed during MBW events, suggesting that the MTM's generation mechanism may be responsible for both phenomena. Questions concerning the PMBW's origins will be addressed later in the modeling sector of this paper.

\section{MTM and $6300 \AA ̊$ airglow modeling}

Attempts at modeling the MTM using a physics based model began with the National Center for Atmospheric Research (NCAR) Thermosphere General Circulation Model (TGCM) described by Dickenson et al. (1981). Even with the inclusion of ion-neutral momentum coupling and solar forcing, these modeling efforts proved unsuccessful until the addition of the interactions between upward propagating lower atmospheric tides and semi-diurnal tides generated in-situ in the thermosphere resulting from ion-neutral momentum coupling as well as solar heating (Fesen et al., 1986). This is in agreement with the Mayr et al. (1979) theory that the MTM is tidal in origin. The TIEGCM is a revised version of TGCM. It is a self-consistent, first principles model which solves the nonlinear, time-dependent equations of hydrodynamics, thermodynamics, electrodynamics, and continuity for the coupled thermosphere-ionosphere system (Richmond et al., 1992). The electrodynamical component includes the calculation of dynamo electric fields and currents along with their feedback into the neutral atmosphere and ionosphere. Tidal waves excited in the lower atmosphere are simulated in the model through the oscillation of its lower boundary at an altitude of $97 \mathrm{~km}$. The state-of-the-art version of TIEGCM for low latitudes described by Fesen et al. (2002) simulates the MTM through the inclusion of upward propagating semidiurnal tidal modes that have been tuned to mimic wind observations made by the Upper Atmospheric Research Satellite (UARS).
In this section, the Fesen et al. (2002) TIEGCM simulations of ion temperature $\left(T_{i}\right)$, electron temperature $\left(T_{e}\right)$, neutral temperature $\left(\mathrm{T}_{\mathrm{n}}\right)$, electron density $\left(\mathrm{N}_{\mathrm{e}}\right)$, atomic oxygen $(\mathrm{O})$, molecular oxygen $\left(\mathrm{O}_{2}\right)$, and molecular nitrogen $\left(\mathrm{N}_{2}\right)$ will be used as inputs to the airglow code described by Mendillo et al. (1993) and Semeter et al. (1996) in order to model $6300 \AA \AA$ airglow emissions in the equatorial region of the American sector. The goal is to simulate PMBW and MBW events observed in the averaged $6300 \AA$ airglow observations (Fig. 4). The geophysical conditions for our modeling study were similar to those for the October 1996 Arequipa and Tucuman data sets: equinox, solar minimum $\left(\mathrm{F}_{10.7}=75\right)$, and magnetically quiet $\left(K_{p}=1\right)$. TIEGCM simulations at $75^{\circ} \mathrm{W}$ longitude were used in our modeling study. The $75^{\circ} \mathrm{W}$ longitude meridian is the closest model grid point to the location of the imaging stations and thus provides the best comparison to the airglow observations presented in Fig. 4.

The airglow code employs the chemical reactions needed to produce the $6300 \AA$ airglow emission which are

$\mathrm{O}_{2}+\mathrm{O}^{+} \stackrel{\mathrm{k}_{3}}{\longrightarrow} \mathrm{O}_{2}^{+}+\mathrm{O}$

$\mathrm{O}_{2}^{+}+\mathrm{e}^{-} \rightarrow \mathrm{O}+\mathrm{O}^{*}$

The excited oxygen, $\mathrm{O}^{*}$, can be in one of two states, $\mathrm{O}\left({ }^{1} \mathrm{D}_{2}\right)$ or $\mathrm{O}\left({ }^{1} \mathrm{~S}_{0}\right)$, depending on its energy. When $\mathrm{O}\left({ }^{1} \mathrm{D}_{2}\right)$ transitions into the $\mathrm{O}\left({ }^{3} \mathrm{P}_{2}\right)$ state, a $6300 \AA$ photon is emitted. The transition from $\mathrm{O}\left({ }^{1} \mathrm{~S}_{0}\right)$ to $\mathrm{O}\left({ }^{1} \mathrm{D}_{2}\right)$ yields a $5577 \AA$ photon and a secondary transition from $\mathrm{O}\left({ }^{1} \mathrm{D}_{2}\right)$ to $\mathrm{O}\left({ }^{3} \mathrm{P}_{2}\right)$ produces another small source of $6300 \AA$ photons. The $6300 \AA$ airglow emission was calculated by integrating the $6300 \AA$ volume emission rate over an altitude range of $100-430 \mathrm{~km}$. This altitude range is determined by the upper and lower altitude boundaries of the TIEGCM. The equation for the volume emission rate is given by

$\eta_{6300}=\frac{\left(\mathrm{A}_{6300}\right)\left(\mathrm{f}\left({ }^{1} \mathrm{D}\right)\right)\left(\mathrm{k}_{3}\right)\left(\mathrm{O}_{2}\right)\left(\mathrm{N}_{\mathrm{e}}\right)}{\mathrm{A}_{{ }_{1} \mathrm{D}}+\text { quench }}$

where $A_{6300}$ is the Einstein transition coefficient for $6300 \AA$ emission, $f\left({ }^{1} D\right)$ is the quantum yield of $\mathrm{O}\left({ }^{1} \mathrm{D}\right)$ for reaction Eq. (5) and $\mathrm{k}_{3}$ is its ion temperature dependent reaction rate; $\mathrm{O}_{2}$ is the molecular oxygen concentration, $\mathrm{N}_{\mathrm{e}}$ is the electron density, and $A_{1}$ is the $O\left({ }^{1} D\right)$ Einstein transition coefficient for photon emission. The model includes quenching from four sources: electrons, atomic oxygen, molecular oxygen and molecular nitrogen. The term "quench" is defined as

quench $=\left(\mathrm{qN}_{2}\right)\left(\mathrm{N}_{2}\right)+\left(\mathrm{qO}_{2}\right)\left(\mathrm{O}_{2}\right)+(\mathrm{qO})(\mathrm{O})+\left(\mathrm{qN}_{\mathrm{e}}\right)\left(\mathrm{N}_{\mathrm{e}}\right)$

where $\mathrm{qN}_{2}, \mathrm{qO}_{2}, \mathrm{qO}$, and $\mathrm{qN}_{\mathrm{e}}$ are the associated quenching coefficients and $\mathrm{N}_{\mathrm{e}}, \mathrm{N}_{2}, \mathrm{O}_{2}$, and $\mathrm{O}$ are the concentrations provided by TIEGCM. Values for the individual parameters are given in Table 1. Further explaination of these prarmeters is given by Semeter et al. (1996). 
Table 1. FES airglow model parameters.

\begin{tabular}{lll}
\hline $\mathrm{A}_{6300}$ & $0.00585 \mathrm{~s}^{-1}$ & Baluja and Zeippen (1988) \\
$\mathrm{A}_{1_{\mathrm{D}}}$ & $0.0077 \mathrm{~s}^{-1}$ & Baluja and Zeippen (1988) \\
$\mathrm{f}\left({ }^{1} \mathrm{D}\right)$ & 1.19 & Semeter et al. (1996) \\
$\mathrm{k}_{3}$ & $3.23 \times 10^{-12} \mathrm{e}^{3.72\left(\frac{300.0}{\mathrm{~T}_{\mathrm{i}}}\right)-1.87\left(\frac{300.0}{\mathrm{~T}_{\mathrm{i}}}\right)^{2}} \mathrm{~cm}^{3} / \mathrm{s}$ & Chen et al. (1978) \\
$\mathrm{qN}_{\mathrm{e}}$ & $8.1 \times 10^{-12}\left(\frac{\mathrm{T}_{\mathrm{e}}}{300.0}\right)^{\frac{1}{2}} \mathrm{~cm}^{3} / \mathrm{s}$ & Link (1982) \\
$\mathrm{qN}_{2}$ & $2.0 \times 10^{-11} \mathrm{e}^{\frac{107.8}{\mathrm{~T}_{\mathrm{n}}}} \mathrm{cm}^{3} / \mathrm{s}$ & Streit et al. (1976) \\
$\mathrm{qO}_{2}$ & $2.9 \times 10^{-11} \mathrm{e}^{\frac{67.5}{\mathrm{~T}_{\mathrm{n}}}} \mathrm{cm}^{3} / \mathrm{s}$ & Streit et al. (1976) \\
$\mathrm{qO}$ & $8.0 \times 10^{-12} \mathrm{~cm}^{3} / \mathrm{s}$ & Abreu et al. (1983) \\
\hline
\end{tabular}

Figure 6 presents the results of the $6300 \AA$ airglow simulation. The format is the same as that used in a meridional intensity scan but encompasses a larger latitude range between $\pm 42.5^{\circ}$. The simulation was successful in reproducing the PMBW event observed in Fig. 4. The observations and modeling results are in good agreement for magnitude and latitudinal range. At $17.5^{\circ} \mathrm{S}$ latitude the magnitude of the observed and modeled PMBWs were 83 and 67 Rayleighs, respectively. In general, a PMBW occurrence spans the latitude range between the Appleton anomaly crest and the magnetic equator. In the simulation, this range is approximately $29^{\circ} \mathrm{S}-11^{\circ} \mathrm{S}$ geographic latitude. In the averaged observations shown in Fig. 4, the full extent of the PMBW event through the southern edge of the anomaly crest is unknown due to inclement weather conditions at Tucuman. However, the averaged latitudinal range of the PMBW is at least $22^{\circ} \mathrm{S}$ to $10^{\circ} \mathrm{S}$. The additional averaged $\mathrm{El}$ Leoncito observations for April 2000 indicate that during April 2000 the anomaly crest was between $30^{\circ} \mathrm{S}$ to $28^{\circ} \mathrm{S}$. PMBW events during the April 2000 time period would, on average, extend between $30^{\circ} \mathrm{S}$ and $11^{\circ} \mathrm{S}$, in agreement with the modeling results. The apparent propagation velocity of the modeled PMBW is slower than observed, as indicated by the slope of the propagation path.

The dashed lines in Fig. 5 plot TIEGCM simulated values at $17.5^{\circ} \mathrm{S}$ latitude at an altitude of $300 \mathrm{~km}$. The latitude grid point was selected for comparison since it is the closest model grid point to that of Arequipa. The peak brightness of the modeled PMBW occurs at 23:15 LT (Fig. 5D), approximately two hours later than in the airglow observations. At this time, other modeled parameters showed no evidence of a neutral temperature enhancement or poleward wind modification suggestive of a common generation mechanism with the MTM. The averaged FPI measurements confirm the absence of such wind and temperature modification during the PMBW's passage.

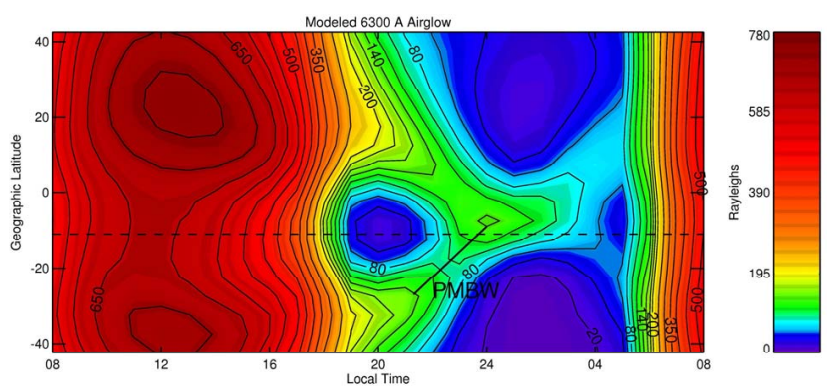

Fig. 6. Modeled $6300 \AA$ airglow. The dashed line indicates the location of the geomagnetic equator. The PMBW event and its equatorward propagation are illustrated by the black line. Note of the lack of an MBW event in the results.

Additional TIEGCM output parameters were examined to gain insight into PMBW production. Figure 7 presents the model results for vertical plasma drifts (A), the maximum electron density at the F-region peak, $\mathrm{N}_{\max }(\mathrm{B})$, and the height of the electron density peak, $h_{\max }(C)$. The magnetic equator is indicated by the solid black line. Together, these three parameters paint a complete picture of the electrodynamics in play in the model when the PMBW was produced. The typical electrodynamics related to the fountain effect are clearly represented. At local noon the vertical plasma drifts (A) show stronger upward values at the magnetic equator than at higher latitudes, moving plasma to higher altitudes at the magnetic equator until gravity dominates and the plasma diffuses down the field lines to higher latitudes. This results in the formation of the anomaly crests which can be seen in $\mathrm{N}_{\max }$ (B). The anomaly crests are observed between 08:00 LT and 22:00 LT. The peak densities of the crests occur near 16:00 LT, centered about the geomagnetic equator at approximately $10^{\circ} \mathrm{N}$ and $30^{\circ} \mathrm{S}$ geographic latitude. A strong pre-reversal enhancement in the vertical plasma drifts occurs 

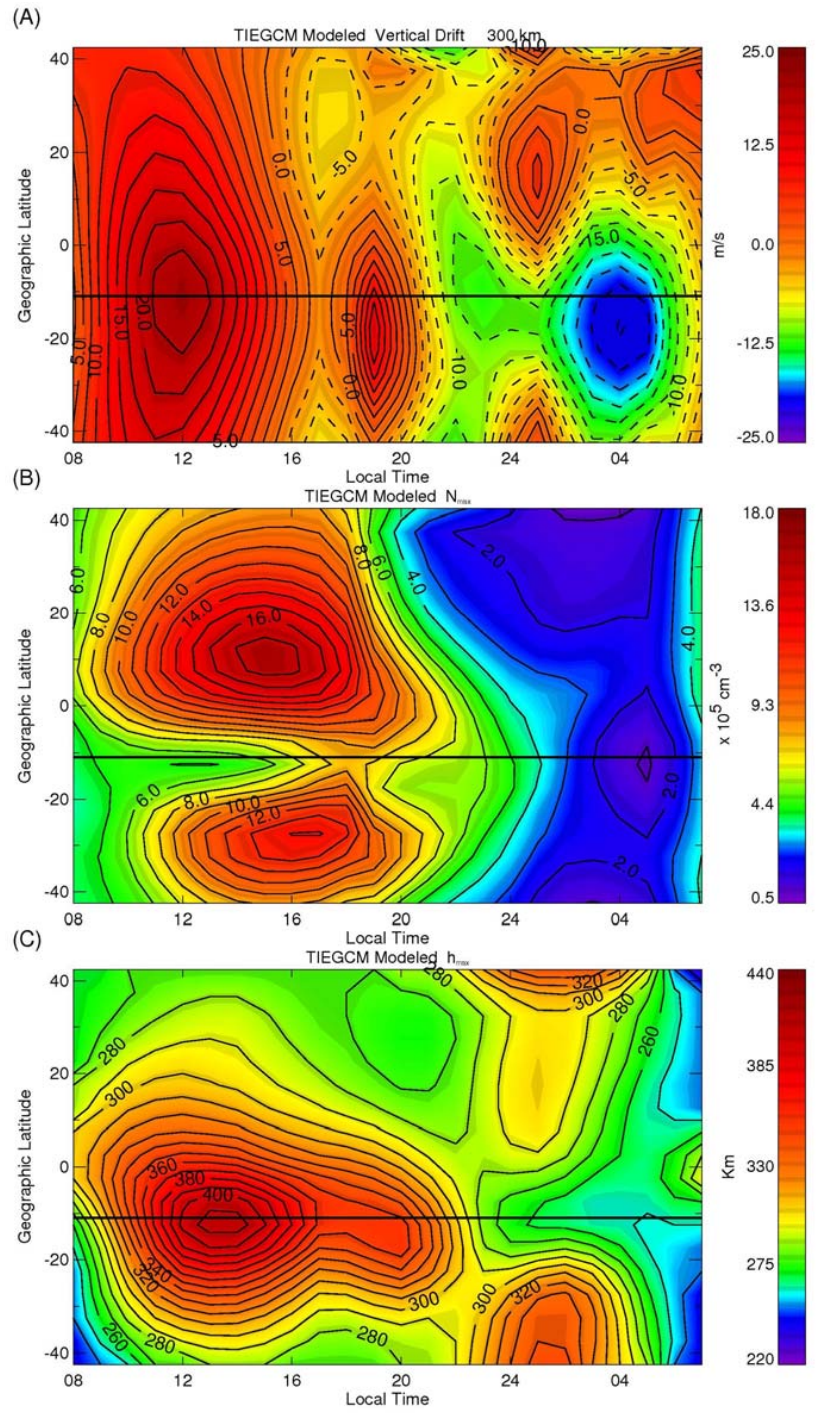

Fig. 7. TIEGCM modeled results for vertical drifts at $300 \mathrm{~km} \mathrm{(A),}$ $\mathrm{N}_{\max }(\mathbf{B})$, and $\mathrm{h}_{\max }(\mathbf{C})$. The solid black line indicates the position of the geomagnetic equator.

at 19:00 LT just south of the magnetic equator. Afterward, between 21:00-22:00 LT, when the fountain effect is reversed and the crests of the anomaly decay, there are slightly smaller downward drifts at the magnetic equator $(\sim-5 \mathrm{~m} / \mathrm{s})$ than at low latitudes in the Southern Hemisphere $(\sim-10 \mathrm{~m} / \mathrm{s})$. This slight difference in the downward drift becomes important in PMBW formation. The plasma at more poleward latitudes drifts down to lower altitudes, recombines, and produces $6300 \AA$ emissions sooner than plasma nearer the magnetic equator. This is also evidenced in $\mathrm{h}_{\max }$. At the time this process occurs, $\mathrm{h}_{\max }$ is lower at more poleward latitudes than at the magnetic equator. This mechanism coincides with the formation of the PMBW in the modeled results. Thus, the modeled PMBW feature results from the earlier dissociative recombination of plasma at low latitudes than that at the magnetic equator, thus producing enhanced $6300 \AA$ emissions sooner at latitudes poleward of the magnetic equator.

To test the dependence of the airglow feature on electrodynamics, a model run was conducted with the pre-reversal enhancement suppressed. Fesen et al. (2002) reported that the strength of the pre-reversal enhancement within the TIEGCM was affected by the electron density specification near the model's lower boundary. The authors found that electron density values of $1500 \mathrm{~cm}^{-3}$ at the model's lower boundary produced a pre-reversal enhancement similar to that observed in the Fejer et al. (1991) seasonally averaged Jicmarca incoherent scatter rader vertical drift measurements. Electron density values nearer $7500 \mathrm{~cm}^{-3}$ appeared to suppress the ocurrence of the pre-reversal enhancement. The model results, shown in Fig. 8A, clearly illustrate that without the pre-reversal enhancement the PMBW does not form. TIEGCM produces an MTM through upward propagating semi-diurnal tides from the lower atmosphere which in turn interact with in-situ semi-diurnal tides excited by ionneutral momentum coupling and solar forcing in the thermosphere. To confirm that the PMBW and the MTM do not share the same generation mechanism, separate model calculations were done with the pre-reversal enhancement included and the upward propagation of the semi-diurnal tides from the lower atmosphere suppressed. The outcome is shown in Fig. 8B. Notice that even with the absence of the upward propagating tides, the PMBW is still reproduced. In summary, under October 1996 solar minimum, magnetically quiet, equinox conditions, the PMBW reproduced in the model is simply a $6300 \AA$ airglow signature of the decay of the intertropical arcs due to the reversal of the equatorial fountain effect.

Figure 6 indicates a conjugate PMBW in the magnetic northern hemisphere. Under magnetically quiet conditions, the intertropical arcs form at approximately symmetric locations about the magnetic equator near $\pm 20^{\circ}$ magnetic latitude. As such, we would expect to observe PMBW events related to the decay of the intertropical arcs in both hemispheres as illustrated in the Fig. 6 modeling results. To date, conjugate PMBW events have not yet been observed in the magnetic northern hemisphere of the American sector primarily due to the lack of all-sky imager coverage at these latitudes.

In examining Fig. 6, we can see that the modeling effort was unsuccessful in reproducing the MBW feature prominent in the averaged $6300 \AA$ airglow data in Fig. 4. As a final point, we now examine other TIEGCM modeled parameters in order to determine the reason for the discrepancy between the model and observations. The modeled neutral temperatures, shown in Fig. 9, illustrate a weak MTM feature centered approximately on the geographic equator at 03:00 LT. This occurrence time is inconsistent with previous observational studies demonstrating that the MTM forms nearer to midnight (Herrero and Spencer, 1982; Bamgboye and 

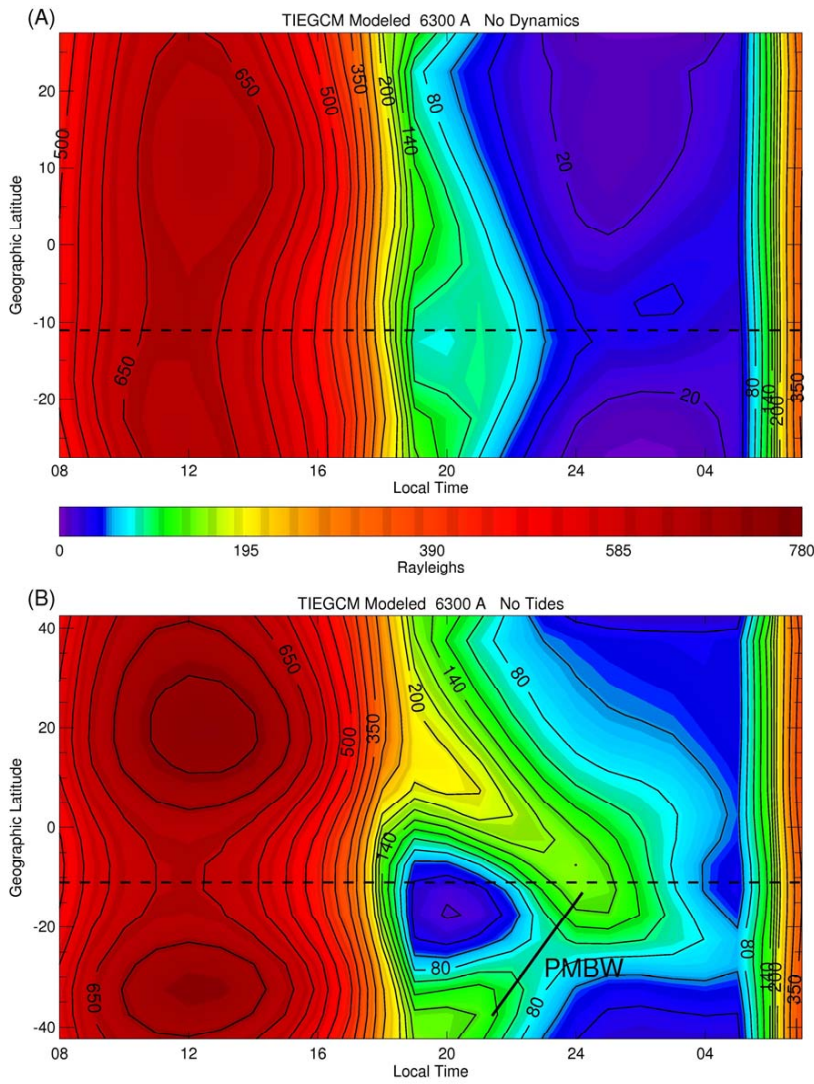

Fig. 8. (A) Modeled $6300 \AA$ emissions with TIEGCM without the inclusion of the pre-reversal enhancement. (B) Modeled $6300 \AA$ emissions without the inclusion of upward propagating tides within TIEGCM. The PMBW and its equatorward propagation are indicated by the solid black line. In both panels, the dashed line indicates the position of the geomagnetic equator.

McClure, 1982; Colerico et al., 1996; Colerico and Mendillo, 2002; Faivre et al., 2005). The averaged FPI temperatures indicated that the MTM developed near midnight, between 00:00-01:30 LT. In comparing the FPI neutral temperature measurements correlated with the observed MBW feature to TIEGCM values at $17.5^{\circ} \mathrm{S}$ (Fig. 5A), we can see that while the FPI data exhibit a strong $200 \mathrm{~K}$ enhancement during the MBW's passage the model produced only a $30 \mathrm{~K}$ enhancement. Colerico et al. (1996) reported temperature enhancements as large as $100-150 \mathrm{~K}$ on individual evenings during MBW events. In Fig. 5B, we see that there is no poleward reversal/abatement in the modeled meridional winds accompanying the weak temperature enhancement. The lack of a modeled MBW feature, as well as the absence of MTM related neutral wind effects, suggests the magnitude of the modeled MTM like feature was not strong enough to cause the modifications in the meridional winds needed to produce the MBW.

While the TIEGCM simulations implemented in the modeling study successfully generated a general MTM feature

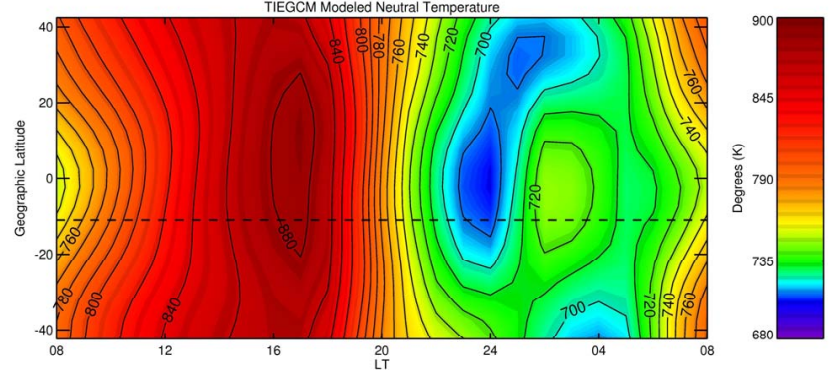

Fig. 9. TIEGCM modeled neutral temperature. A weak MTM feature can be seen approximately centered on the geographic equator near 03:00 LT. The dashed line indicates the location of the geomagnetic equator.

at the equator via a combination of lower atmospheric semidiurnal tidal modes (Fesen et al., 1986, 2002), it was not able to reproduce basic observed properties such as amplitude and latitudinal structure. This suggests the additional tidal modes or processes may contribute to the MTM's overall development. Mayr et al. (1979) conducted a Fourier analysis of neutral temperature measurements taken by the Neutral Atmosphere Temperature Experiment (NATE) instrument aboard the AE-E satellite. The authors reported that even though the semi-diurnal component of lower atmospheric tides plays a dominant role in the formation of the MTM, other tidal modes warranted examination. Their analysis indicated that observed temperature variations related to the MTM could be basically described with the first three tidal modes and more accurately with the inclusion of the fourth and fifth modes. Herrero et al. (1983) also conducted a tidal analysis of NATE temperature data in order to explain the MTM's latitudinal (seasonal) structure. The authors determined that observed latitudinal (seasonal) variations were due to the semidiurnal and terdiurnal components of the lower atmospheric tides. These two earlier investigations suggest that higher order tidal modes, which may not be well represented within the TIEGCM, may play a small but significant role in the MTM's overall development.

\section{Conclusions}

We have presented the first evidence of MTM/MBW propagation from the geographic equator into mid-latitudes past $39^{\circ} \mathrm{S}$. This suggests that significant low-to-mid latitude coupling of the thermosphere-ionosphere system exists during MTM events due to the closely coupled nature of its fundamental parameters. Averaged FPI measurements taken at Arequipa during October 1996 indicate the occurrence of an MTM having a magnitude of approximately $200 \mathrm{~K}$ accompanied by a poleward increase in the meridional winds on the order of $80 \mathrm{~m} / \mathrm{s}$. These features are correlated with the passage of an MBW in the October 1996 monthly averaged 
$6300 \AA$ emission, reaffirming the relationship between the MTM and the MBW.

Our airglow modeling efforts were successful in reproducing a PMBW event similar in magnitude, local time duration, and latitudinal range to the October 1996 averaged PMBW observations. The modeled PMBW occurrence time lagged the observations by approximately $1.5 \mathrm{~h}$. The examination of TIEGCM modeled vertical plasma drifts, $\mathrm{N}_{\max }$, and $\mathrm{h}_{\max }$ indicate that the PMBW results from the relaxation of the intertropical arcs due to the reversal of the fountain effect. The results of two additional $6300 \AA$ airglow simulations employing TIEGCM, one in which the upward propagating tidal modes were omitted and the other without the inclusion of the pre-reversal enhancement, confirm the PMBW's electrodynamic origins.

Efforts to model the MBW phenomenon, employing the Fesen et al. (2002) TIEGCM simulations of $T_{i}, T_{e}, T_{n}, N_{e}$, $\mathrm{O}, \mathrm{O}_{2}$, and $\mathrm{N}_{2}$ in conjunction with the airglow model, proved unsuccessful. Examination of model output revealed only a weak MTM-like feature $(\sim 30 \mathrm{~K})$, along with a distinct absence of the MTM's signature poleward modification in the meridional winds. The occurrence time of the modeled temperature enhancement near 03:00 LT lagged the observations by approximately $1.5 \mathrm{~h}$. We suggest that the magnitude of the modeled MTM was simply too weak to instigate the modification in the meridional winds needed to produce and MBW. Incorporation of higher order tidal modes in TIEGCM at its lower boundary may be necessary in order to accurately simulate the MTM and its observed characteristics.

Acknowledgements. This study was supported by NSF Aeronomy Program and Office of Naval Research grants to Boston University. The authors would like to thank J. Baumgardner, and C. Martinis for their assistance in all-sky imager instrumentation, M. Biondi for his technical expertise and assistance in Fabry-Perot instrumentation, the professional staff and colleagues at Arequipa, University of Tucuman, and CONICET/El Leoncito Observatory for their assistance, and A. Coster for her scientific expertise.

Topical Editor M. Pinnock thanks I. S. Batista and F. Herrero for their help in evaluating this paper.

\section{References}

Abreu, V. J., Solomon, S. C., Sharp, W. E., and Hays, P. B.: The dissociative recombination of $\mathrm{O}_{2}^{+}$: The quantum yield of $\mathrm{O}\left({ }^{1} \mathrm{~S}\right)$ and $\mathrm{O}\left({ }^{1} \mathrm{D}\right), \mathrm{J}$. Geophys. Res., 88, 4140-4144, 1983.

Baluja, K. L. and Zeippen, C. J.: M1 and E2 transition probabilities for states within the $2 \mathrm{p} 4$ configuration of the OI isoelectric sequence, J. Phys. B., 21, 1455-1471, 1988.

Bamgboye, D. K. and McClure, J. P.: Seasonal variations in the occurrence time of the equatorial midnight temperature buldge, Geophys. Res. Lett., 9, 457-460, 1982.

Baumgardner, J., Flynn, B., and Mendillo, M.: Monochromatic imaging instrumentation for applications in Aeronomy of the Earth and planets, Optical Engineering, 32, 3028-3032, 1993.
Behnke, R. A. and Harper, R. M.: Vector measurements of F-region ion transport at Arecibo, J. Geophys. Res., 78 (34), 8222-8234, 1973.

Biondi, M. A., Meriwether, J. M., Fejer, B. G., and Gonzales, S. A.: Seasonal variations in the equatorial thermospheric wind at Arequipa, Peru, J. Geophys. Res., 95, 12 243-12 250, 1990.

Biondi, M. A., Meriwether, J. M., Fejer, B. G., Gonzales, S. A., and Hallenbeck, D. C.: Equatorial thermospheric wind changes during the solar cycle: Measurements from Arequipa, Peru from 1983 to 1990, J. Geophys. Res., 96, 15917-15 930, 1991.

Burnside, R. G., Herrero, F. A., Meriwether, J. W., and Walker, J. C. G.: Optical observations of thermospheric dynamics at Arecibo, J. Geophys. Res., 86, 5532-5540, 1981.

Chen, A., Johnsen, R., and Biondi, M. A.: Measurements of the $\mathrm{O}^{+}+\mathrm{N}_{2}$ and $\mathrm{O}^{+}+\mathrm{O}_{2}$ reaction rates from 300 to $900 \mathrm{~K}$, J. Chem. Phys., 69, 2688-2691, 1978.

Colerico, M. J., Mendillo, M., Nottingham, D., Baumgardner, J., Meriwether, J., Mirick, J., Reinisch, B. M., Scali, J. L., Fesen, C. G., and Biondi, M. A.: Coordinated measurements of F-region dynamics related to the thermospheric midnight temperature maximum. J. Geophys. Res., 101 (A12), 26 783-26 793, 1996.

Colerico, M. J. and Mendillo, M.: The current state of investigations regarding the thermospheric midnight temperature maximum (MTM), J. Atmos. S.-P., 64, 1361-1369, 2002.

Dickinson, R. E., Ridley, E. C., and Roble, R. G.: A three dimensional general circulation model of the thermosphere. J. Geophys. Res., 86, 1499-1512, 1981.

Faivre, M., Meriwether, J. W., Fesen, C., and Biondi, M. A.: Climatology of the midnight temperature maximum phenomenon at Arequipa, Peru, J. Geophys. Res., in press, 2006.

Fejer, B. G., de Paula, E. R., Gonzalez, S. A., and Woodman, R. F.: Average vertical and zonal $F$ region plasma drifts over Jicamarca, J. Geophys. Res., 96(A8), 13 901-13 906, 1991.

Fesen, C. G., Hysell, D. L., Meriwether, J. W., Mendillo, M., Fejer, B. G., Roble, R. G., Reinisch, B. W., and Biondi, M. A.: Modeling of the low latitude thermosphere and ionosphere, J. Atmos. S.-P., 64, 1337-1349, 2002.

Fesen, C. G., Dickinson, R. E., and Roble, R. G.: Simulation of the thermospheric tides at equinox with the National Center for Atmospheric Research thermospheric general circulation model, J. Geophys. Res., 91, 4471-4489, 1986.

Herrero, F. A., Mayr, H. G., and Spencer, N. W.: Latitudinal (seasonal) variations in the thermospheric midnight temperature maximum: a tidal analysis, J. Geophys. Res., 88 (A9), 72257235, 1983.

Herrero, F. A., Mayr, H. G., Spencer, N. W., Hedin, A. E., and Fejer, B. G.: Interaction of zonal winds with the equatorial midnight pressure bulge in the Earth's thermosphere: empirical check of momentum balance, Geophys. Res. Lett., 12, 491-494, 1985.

Herrero, F. A. and Spencer, N. W.: On the horizontal distribution of the equatorial thermospheric midnight temperature maximum and its seasonal variations, Geophys. Res. Lett., 9, 1179-1182, 1982.

Herrero, F. A., Spencer, N. W., and Mayr, H. G.: Thermosphere and F-region plasma dynamics in the equatorial region, Adv. Space R., 13, 201-220, 1993.

Link, R.: Dayside magnetospheric cleft auroral processes, Ph.D. Thesis, York University, Toronto, Canada, 1982. 
Mayr, H. G., Harris, I., Spencer, N. W., Hedin, A. E., Wharton, L. E., Potter, H. S., Walker, J. C. G., and Carlson, H. C.: Tides and the midnight temperature anomaly in the thermosphere, Geophys. Res. Lett., 6, 447-450, 1979.

Meriwether, J. W., Moody, J. W., Biondi, M. A., and Roble, R. G.: Optical interferometric measurements of nighttime equatorial thermospheric winds at Arequipa. J. Geophys. Res., 91, 5557-5566, 1986.

Mendillo, M., Semeter, J., and Noto, J.: Finite element simulation (FES): a computer modeling technique for studies of chemical modification of the ionosphere, Adv. Space Res., 13, (10)55(10)64, 1993.

Mendillo, M., Baumgardner, J., Colerico, M., and Nottingham, D.: Imaging Science contributions to equatorial aeronomy: initial results from the MISETA program, J. Atmos. S.-P., 59, 1587-1599, 1997.

Nelson, G. J. and Cogger, J. J.: Dynamical behavior of the nighttime ionosphere over Arecibo. Journal of Atmospheric and Terrestrial Physics, 33, 1711-1726, 1971.

Rao, H. N., Ranganath, S., and Hanumath, J.: Characteristics of the equatorial midnight temperature maximum in the Indian sector, Ann. Geophys., 12, 276-278, 1994.
Rees, M. H.: Physics and chemistry of the upper atmosphere, Cambridge University Press, 1989.

Richmond, A. D., Ridley, E. C., and Roble, R. G.: A thermosphere/ionosphere general circulation model with coupled dynamics, Geophys. Res. Lett., 19, 601-604, 1992.

Semeter, J., Mendillo, M., Baumgardner, J., Holt, J., Hunton, D. E., and Eccles, V.: A study of oxygen $6300 \AA$ airglow production through chemical modification of the nighttime ionosphere, J. Geophys. Res., 101, 19683-19699, 1996.

Sobral, J. H. A., Carlson, H. C., Farley, D. T., and Swartz, W. E.: Nighttime dynamics of the F-region near Arecibo as mapped by airglow features, J. Geophys. Res., 83 (A6), 2561-2566, 1978.

Spencer, N. W., Carignan, G. R., Mayr, H. G., Neimann, H. B., Theis, R. F., and Wharton, L. E.: The midnight temperature maximum in the Earth's equatorial thermosphere, Geophys. Res. Lett., 6 (6), 444-446, 1979.

Streit, G. E., Carleton, J. H., Schmeltekopf, A. L., Davidson, J. A., and Schiff, H. I.: Temperature dependence of $\mathrm{O}\left({ }^{1} \mathrm{D}\right)$ rate constants for reactions with $\mathrm{O}_{2}, \mathrm{~N}_{2}, \mathrm{CO}_{2}, \mathrm{O}_{3}$, and $\mathrm{H}_{2} \mathrm{O}$, J. Chem. Phys., 65, 4761-4764, 1976. 